\title{
Glaucoma in Penetrating Keratoplasty
}

\section{Prateeksha Sharma*}

Eye Specialist, Employee's State Insurance Corporation Hospital, IMT Manesar, Haryana, India

*Corresponding Author: Prateeksha Sharma, Eye Specialist, Employee's State Insurance Corporation Hospital, IMT Manesar, Haryana, India.
Received: January 19, 2021

Published: March 22, 2021

(C) All rights are reserved by Prateeksha

Sharma.

\begin{abstract}
Glaucoma following penetrating keratoplasty (PKP) is one of the most common causes for irreversible visual loss [1] and the second leading cause for graft failure after rejection [2]. The management of penetrating keratoplasty and glaucoma remains controversial mainly because of the high risk of graft failure associated with treatment.
\end{abstract}

Keywords: Penetrating Keratoplasty (PKP); Glaucoma; IOP

\section{Introduction}

Penetrating keratoplasty is complicated by a significant incidence of IOP elevation in both the early and late postoperative periods, although reported incidences vary considerably. One study revealed a $31 \%$ incidence of early post-operative increase in IOP and a $29 \%$ incidence of late ( $>3$ months) increase [3]. Another large survey had a $9 \%$ incidence of immediate postoperative glaucoma and an 18\% incidence of chronic post-keratoplasty glaucoma [1]. It was also found that chronic glaucoma was more likely to occur in eyes that had been reported to have early postoperative pressure rise [4].

\section{Associated factors}

Factors associated with glaucoma after penetrating keratoplasty in various studies include [1,3-8]:

- Recipient age older than 60 years

- Aphakia

- Pre-existing glaucoma

- Preoperative diagnosis of adherent leukoma

- Bullous keratopathy
- Herpetic keratitis

- Trauma

- Associated vitrectomy

- Anterior segment reconstruction.

The average maximum pressure reported in a study within the first week was $24 \mathrm{~mm} \mathrm{Hg}$ in phakic eyes, $40 \mathrm{~mm} \mathrm{Hg}$ in aphakic eyes, and $50 \mathrm{~mm} \mathrm{Hg}$ in eyes that had combined cataract extraction and keratoplasty [9]. When keratoplasty was combined with cataract extraction, the incidence of glaucoma was higher with intracapsular extraction than with extracapsular surgery [10].

The incidence of post-keratoplasty glaucoma is also increased after repeated penetrating keratoplasty [11].

\section{Pathophysiology}

Early postoperative period

In some cases, the postoperative glaucoma after penetrating keratoplasty has similar IOP elevating mechanisms that are associated with other intraocular procedures including uveitis, hemorrhage, pupillary block, and steroid-induced glaucoma [12]. How-

Citation: Prateeksha Sharma. "Glaucoma in Penetrating Keratoplasty". Acta Scientific Ophthalmology 4.4 (2021): 223-227. 
ever, additional mechanisms of early postoperative glaucoma are unique to eyes that have undergone penetrating keratoplasty, especially when aphakia is also present. Two such mechanisms have been postulated.

Collapse of the trabecular meshwork: Collapse of the trabecular meshwork may result from the loss of anterior support due to the incision in the Descemet membrane, which may be compounded in the aphakic eye by a reduction in posterior support from the loss of zonular tension $[13,14]$. This hypothesis is supported by the observation that full thickness suturing in one study was associated with better aqueous outflow in autopsy eyes and lower early postoperative IOP, compared with conventional suturing [13,14]. Some surgeons, however, report less postoperative pressure rise with use of partial thickness sutures, which they believe prevents angle distortion [15].

Compression of the anterior chamber angle: Compression of the anterior chamber angle may be caused by the conventional techniques of penetrating keratoplasty, causing an early postoperative IOP rise and subsequent chronic glaucoma due to peripheral anterior synechiae $[15,16]$.

\section{Late postoperative period}

Gradual flattening of the anterior chamber several months after aphakic keratoplasty has been reported [17]. This appears to be related to presence of an intact anterior vitreous face, and prophylactic vitrectomy has been suggested to avoid this complication. IOP elevation may also occur in association with graft rejection, which may require long-term steroid and antiglaucoma therapy [18]. Pigment dispersion syndrome may also be seen with pseudophakic eyes that have undergone corneal transplantation. In these patients, the syndrome has the unique feature of an inferior linear pigmented endothelial line, which can be confused with graft reaction [19]. Another late-developing glaucoma occurs after keratoplasty for congenitally opaque corneas [20]. It is not associated with peripheral anterior synechiae and the mechanism is unknown. Other forms of late-onset glaucoma may result from peripheral anterior synechiae, the long-term use of steroids, or epithelial ingrowth $[12,21]$.

\section{Diagnosis}

Accurate measurement of IOP, assessment of visual fields and neuroretinal structures are often not possible before PK due to the primary corneal disease. This often leads to an inability to diagnose pre-existing glaucomatous optic neuropathy. Following PK, changes in corneal thickness, post-operative astigmatism and refractive changes often preclude reliable post- operative assessment of IOP, disc and visual field.

The diagnosis of post-PK glaucoma is primarily based on IOP measurements in the early post-operative period, and on IOP, optic disc change and progressive visual field changes in the late postoperative period. IOP in the early post- operative period, when the corneal surface is irregular, can be measured with the Mackay-Marg electronic applanation tonometer, the pneumatic applanation tonometer, the tono-pen, or recently the dynamic contour tonometer (DCT), independent of the corneal thickness. If the graft surface is smooth with an intact epithelium and regular mires can be obtained, then Goldmann applanation can be used to measure the IOP.

\section{Management}

Preventive measures

Angle compression can be minimized and trabecular support improved by employing following strategies:

- Donor graft that is larger than the recipient trephine

- Looser or shorter suture bites to minimize tissue compression

- Smaller trephine size

- Thinner peripheral host cornea

- Larger host corneal diameter [16,22].

Reports conflict regarding whether an oversized corneal donor graft improves outflow and reduces postkeratoplasty glaucoma. A perfusion study with autopsy eyes revealed no improvement in outflow, and the use of 0.5 -mm oversized grafts in a clinical series afforded no protection against postoperative glaucoma [23,24]. However, other clinical studies indicate that the use of oversized grafts is associated with deeper anterior chamber depths, a lower incidence of progressive angle closure, and significantly lower postoperative pressures, compared with use of same-sized grafts [25-28]. Oversized grafts, however, are contraindicated in treating keratoconus because they cause a significant increase in myopia [29]. Another technique to prevent postkeratoplasty angle-closure glaucoma is the placement of sutures near the pupillary portion of a flaccid iris to create a taut iris [30]. In addition, glaucoma after 
keratoplasty can be minimized by using meticulous wound closure and extensive postoperative steroids [31] (with caution for steroid responsive patients).

\section{Treatment of glaucoma}

Medical therapy

Medical therapy should be tried first, unless a specific, treatable condition, such as pupillary block, is apparent. However, attempts to alter the early postoperative pressure rise are frequently unsuccessful. Carbonic anhydrase inhibitors were not found to be significantly efficacious in this situation [32], although they may be useful in treating the chronic glaucoma. Reported results with timolol have been conflicting [32], although the drug does appear to have some value, especially in controlling chronic glaucoma after keratoplasty [12]. Miotics may occasionally be of value.

\section{Surgical therapy}

Surgical therapy is indicated when the optic nerve head or the graft is threatened by a persistently elevated IOP. No glaucoma operation has been found to be entirely suitable for controlling IOP and preserving graft clarity. One investigation found a $30 \%$ incidence of graft failure after any intraocular procedure [33]. When penetrating keratoplasty was performed after trabeculectomy in one series, the 5-year probability of successfully maintaining IOP control and a clear graft was only $27 \%$, which increased to $50 \%$ in another series of combined trabeculectomy and penetrating keratoplasty [34]. Implantation of a Molteno drainage device achieved IOP control of $21 \mathrm{~mm} \mathrm{Hg}$ or less with one or more procedures in a series of 17 eyes, although seven had allograft rejections [35]. In another series, involving 26 eyes with glaucoma drainage devices, final IOP was less than $18 \mathrm{~mm} \mathrm{Hg}$ in $96 \%$ of the eyes but graft failure occurred in 42\% [36]. Cyclocryotherapy was once the most commonly used surgical procedure for glaucoma after penetrating keratoplasty [37], although the high incidence of serious complications limits its usefulness. Transscleral cyclophotocoagulation has largely replaced cyclocryotherapy as the cyclodestructive procedure of choice. However, in one series of 39 patients, $77 \%$ had a final IOP between 7 and $21 \mathrm{~mm} \mathrm{Hg}$, but $44 \%$ of those with clear grafts before cyclophotocoagulation had graft decompensation [38].

\section{Conclusion}

Raised IOP post keratoplasty leads to poor vision and ultimately graft failure. So it is very essential to measure IOP on regular basis.
Prompt steps to be taken if found high and should be managed aggressively which can save the graft as well as eye.

\section{Bibliography}

1. Foulks GN. "Glaucoma associated with penetrating keratoplasty". Ophthalmology 94 (1987): 871-874.

2. Wilson SE and Kaufman HE. "Graft failure after penetrating keratoplasty". Survey of Ophthalmology 34 (1990): 325-356.

3. Karesh JW and Nirankari VS. "Factors associated with glaucoma after penetrating keratoplasty". American Journal of Ophthalmology 96 (1983): 160-164.

4. Olson RF and Kaufman HE. "Prognostic factors of intraocular pressure after aphakic keratoplasty". American Journal of Ophthalmology 86 (1978): 510.

5. Goldberg DB., et al. "Incidence of increased intraocular pressure after keratoplasty”. American Journal of Ophthalmology 92 (1981): 372-377.

6. Sihota R., et al. "Post-penetrating keratoplasty glaucoma: risk factors, management and visual outcome". Australian and New Zealand Journal of Ophthalmology 26 (1998): 305-309.

7. Allouch C., et al. "Incidence and factors influencing glaucoma after penetrating keratoplasty [in French]". Journal Français D’Ophtalmologie 26 (2003): 553-561.

8. Franca ET., et al. "A study of glaucoma after penetrating keratoplasty". Cornea 21 (2002): 284-288.

9. Irvine AR and Kaufman HE. "Intraocular pressure following penetrating keratoplasty". American Journal of Ophthalmolog 68 (1969): 835-844.

10. Brightbill FS., et al. "A comparison of intracapsular and extracapsular lens extraction combined with keratoplasty". Ophthalmology 90 (1983): 34-37.

11. Robinson $\mathrm{CH}$ Jr. "Indications, complications and prognosis for repeat penetrating keratoplasty". Ophthalmic Surgery 10 (1979): 27-34.

12. Lass JH and Pavan-Langston D. "Timolol therapy in secondary angle-closure glaucoma post penetrating keratoplasty". Ophthalmology 86 (1979): 51-59. 
13. Zimmerman TJ., et al. "The effect of suture depth on outflow facility in penetrating keratoplasty". Archives of Ophthalmology 96 (1978): 505-506.

14. Zimmerman TJ., et al. "Intraocular pressure after aphakic penetrating keratoplasty "through-and-through" suturing". Ophthalmic Surgery10 (1979): 49-52.

15. Nissenkorn I and Wood TO. "Intraocular pressure following aphakic transplants". Annals of Ophthalmology 15 (1983): 1168-1171.

16. Olson RJ and Kaufman HE. "A mathematical description of causative factors and prevention of elevated intraocular pressure after keratoplasty". Investigative Ophthalmology and Visual Science 16 (1977): 1085-1092.

17. Gnad HD. "Athalamia as a late complication after keratoplasty on aphakic eyes". British Journal of Ophthalmology 64 (1980): 528-530.

18. Polack FM. "Graft rejection and glaucoma”. American Journal of Ophthalmology 101 (1986): 294-297.

19. Insler MS and Mc Shrerry Zatzkis S. "Pigment dispersion syndrome in pseudophakic corneal transplants". American Journal of Ophthalmology 102 (1986): 762-765.

20. Schanzlin DJ., et al. "Transplantation of congenitally opaque corneas". Ophthalmology 87 (1980): 1253-1264.

21. Yamaguchi T., et al. "Electron microscopic study of epithelial downgrowth after penetrating keratoplasty". British Journal of Ophthalmology 65 (1981): 374-382.

22. Olson RJ. "Aphakic keratoplasty: determining donor tissue size to avoid elevated intraocular pressure". Archives of Ophthalmology 96 (1978): 2274-2276.

23. Zimmerman TJ., et al. "Size of donor corneal button and outflow facility in aphakic eyes". Annals of Ophthalmology 11 (1979): 809-811.

24. Perl T., et al. "Disparate diameter grafting: astigmatism, intraocular pressure, and visual acuity". Ophthalmology 88 (1981): 774-781.
25. Heidemann DG., et al. "Oversized donor grafts in penetrating keratoplasty: a randomized trial". Archives of Ophthalmology 103 (1985): 1807-1811.

26. Foulks GN., et al. "Oversize corneal donor grafts in penetrating keratoplasty". Ophthalmology 86 (1979): 490-494.

27. Zimmerman T., et al. "Transplant size and elevated intraocular pressure: postkeratoplasty". Archives of Ophthalmology 96 (1978): 2231-2233.

28. Bourne WM., et al. "The effects of oversize donor buttons on postoperative intraocular pressure and corneal curvature in aphakic penetrating keratoplasty". Ophthalmology 89 (1982): 242-246.

29. Perry HD and Foulks GN. "Oversize donor buttons in corneal transplantation surgery for keratoconus”. Ophthalmic Surgery 18 (1987): 751-752.

30. Cohen EJ., et al. "Iridoplasty for prevention of postkeratoplasty angle closure and glaucoma". Ophthalmic Surgery 13 (1982): 994-996.

31. Thoft RA., et al. "Glaucoma following keratoplasty". Transactions - American Academy of Ophthalmology and Otolaryngology 78 (1974): 352-364.

32. Olson RJ., et al. "Effects of timolol and Daranide on elevated intraocular pressure after aphakic keratoplasty". Annals of Ophthalmology 11 (1979): 1833-1836.

33. Lemp MA., et al. "The effect of intraocular surgery on clear corneal grafts". American Journal of Ophthalmology 70 (1970): 719-721.

34. Kirkness CM., et al. "Coexistent corneal disease and glaucoma managed by either drainage surgery and subsequent keratoplasty or combined drainage surgery and penetrating keratoplasty". British Journal of Ophthalmology 76 (1992): 146-152.

35. McDonnell PJ., et al. "Molteno implant for control of glaucoma in eyes after penetrating keratoplasty". Ophthalmology 95 (1988): 364-369.

36. Sherwood MB., et al. "Drainage tube implants in the treatment of glaucoma following penetrating keratoplasty". Ophthalmic Surgery 24 (1993): 185-189. 
37. Binder PS., et al. "Cyclocryotherapy for glaucoma after penetrating keratoplasty". American Journal of Ophthalmology 79 (1975): 489-492.

38. Threlkeld $\mathrm{AB}$ and Shields $\mathrm{MB}$. "Noncontact transscleral $\mathrm{Nd}$ :YAG cyclophotocoagulation for glaucoma after penetrating keratoplasty". American Journal of Ophthalmology 120 (1995): 569-576.

\section{Assets from publication with us}

- Prompt Acknowledgement after receiving the article

- Thorough Double blinded peer review

- Rapid Publication

- Issue of Publication Certificate

- High visibility of your Published work

Website: www.actascientific.com/ Submit Article: www.actascientific.com/submission.php Email us: editor@actascientific.com Contact us: +919182824667 